\title{
Acute and chronic effect of stretching exercise on posture and flexibility of nurses and licensed practical nurses
}

\author{
José Nunes da Silva Filho(1), Jonas Lírio Gurgel(2), Elirez Bezerra da Silva ${ }^{(3)}$, Flávia Porto ${ }^{(4)}$
}

\begin{abstract}
Introduction: nurses and licensed practical nurses are among the most affected by postural deviations and their drawbacks, in the world. One of the ways to mitigate these ills is physical exercise, and it can be done at work environment, however, not as a form of workout gymnastics. Objective: To verify the effects of a muscle stretching exercise program (MSE) on posture and flexibility of nurses. Methods: Controlled clinical experiment with 28 nurses, aged 18-60 years, divided into experimental group ( $n=15)$ and control group $(n=13)$. Anthropometric measures, flexibility and body posture of the trunk were performed. The intervention was of 08 weeks of MSE; each session lasted $40 \mathrm{~min}$. The exercises had four sets of $30 \mathrm{~s}$ of tension for $30 \mathrm{~s}$ of the interval. An independent t-test compared the characteristics of the samples. The chi-square test treated the results regarding body posture, and the level of significance was $p \leq 0.05$. Results: MSE promoted positive and chronic positive changes in the Experimental Group with attenuation of the concavities of the vertebral column in the cervical and thoracic regions. In the alignment of the cervical region and the curvature of the lumbar region, the effects were observed after the eight weeks of training, including sharp reduction of gibbosity in the scapula region after the exercise session. Conclusion: MSE promoted acute and chronic positive changes in body posture and flexibility in nurses.
\end{abstract}

Keywords: Occupational Health. Health Promotion. Moire Topography. Goniometry.

\section{INTRODUCTION}

Postural changes have been investigated because they may endanger the health and quality of life and are related to the interruption of their usual activities and pain ${ }^{(1)}$.

These postural changes seem to be strongly correlated with certain posture maintenance for long periods ${ }^{(2)}$ and inadequate postures in work activities ${ }^{(3)}$. These factors, therefore, contribute to the onset of functional postural deviations, since, according Paccini, Cyrino and Glaner (4), functional postural deviations are originate from tasks and/or vicious habits at home or in the workplace, and structural postural deviations appear when some bone, joint or muscular structure appears to be non-uniform, anatomically.

Currently, functional postural deviations affect a large portion of the worldwide population, being the origin of musculoskeletal problems, according to the World Health Organization ${ }^{(5)}$, associated with ergonomic and traumatic factors. In labor terms, it is estimated that among the professional classes most affected by postural changes, are the nurses. According to Marziale et al. ${ }^{(6)}$, these professionals accept in their work activities, certain postures for prolonged periods of time, which trigger several musculoskeletal problems and pain, especially in the cervical, dorsal and lumbar regions. Engels et al. ${ }^{(7)}$ observed that the nurses are approximately $20 \%$ of their working hours in harmful postures, which cause more physical effort and greater probability of musculoskeletal damage.

The nurses frequently complain about their work equipment ${ }^{(8)}$, alleging poor litter wheel lubrication, chair and crank beds; the heights of some equipment are different as beds and stretchers, wheelchairs and bath chairs, among others ${ }^{(9)}$. In addition to ergonomically inadequate equipment, the work activities of the nurses require high physical overload with repetitive movements. In the study by Zanon and Marziale ${ }^{(9)}$, it was reported that more than $90 \%$ of the evaluated workers, performed physical effort with the spine inclination for carrying out their tasks and more than $85 \%$ twisted, stretched and flexed repeatedly the trunk to carry extra loads.

It is known that muscle stretching exercises have been suggested in various clinical interventions aimed at promoting health as complementary treatment of musculoskeletal injuries $^{(10)}$ and attenuation of postural deviations ${ }^{(11)}$, however, 
still there is no consensus about its real benefits ${ }^{(12,13)}$. What is known is that the prescription of muscle stretching exercises, although in some cases does not present significant results in body posture, may contribute to the reduction of back pain ${ }^{(14)}$. And in the case of nurses, data from the American Nurses Association demonstrate that approximately $90 \%$, all over the world, feel nonspecific pain in some part of the body, generating frequently, absence from work ${ }^{(15)}$.

Regarding the prescription of Muscle Stretching Exercises (MSE) for postural deviation correction, there are still questions about the most appropriate prescription and, therefore, about its real benefits on the bipedal posture ${ }^{(12)}$. These doubts difficult to interpret the studies outcomes and may be explained by little or no reliability employee postural assessment method ${ }^{(13)}$, for the suggested training with nonspecific prescription ${ }^{(16)}$ or even by the lack of methodological description in the studies, making it difficult, thus, that they are replicated ${ }^{(12)}$ or compared.

In this study, it was proposed to verify the muscle stretching exercises effects on body posture and flexibility in nurses. The hypothesis was that muscle stretching exercises may cause positive changes in body posture and flexibility of these professionals, soon after exercise (acute effect) and during eight weeks of training (chronic effect).

\section{MATERIALS AND METHODS}

The study is a controlled clinical experiment of descriptive, inferential and longitudinal character. The study followed Resolution 466 of December 12, 2012 of the Brazilian National Health Council on guidelines for research involving human beings, and its approval by the Research Ethics Committee of the Faculty of Medicine of the Fluminense Federal University, through the Protocol Number: 679.764/2014.

The sample consisted of 28 nurses, of a population of 32 employees of a polyclinic in the Niterói city-RJ. The volunteers were aged 18 to 60 years old, had some postural deviation and were not practicing any physical activity during the period of participation in the study. The volunteers were selected by convenience and then allocated to two groups: experimental group (EG: $n=15$ ) and control group (CG: $n=13$ ), by a sequence of random numbers generated by the 'random' function of the Microsoft Office Excel 2007.

\section{Procedures}

In the first stage, pre- and post-intervention acute evaluations (only one session of stretching exercises) were performed. In the second stage, after 8 weeks of stretching exercises performed only by the EG, both groups were reevaluated.

The individuals allocated to the CG underwent the same evaluations as the EG, however, did not participate in the MSE sessions. At the end of the study, individual reports containing the results of all measurements were made available to the study participants.

\section{Anthropometry}

In order to describe the sample characteristics, height, body mass, abdominal perimetry (AP) and body mass index (BMI) were measured according to the recommendations of the International Standards for Anthropometric Assessment.

\section{Postural evaluation with the Moiré de Sombra technique (MST)}

The methodological design to obtain the Moire Topography obeyed the proposal of Porto et al. (17). Thus, a photographic camera (Sony, model Ciber-shot, $14.1 \mathrm{mp}$, model Psc w350, Manaus, AM, Brazil) was fixed to a tripod, a light source (100 W, Bellalux, Osasco, SP, Brazil) constructed with nylon wires (Grilon 210/36, 1.35 mm, 200 g, São Paulo, SP, Brazil) with a period of $1 \mathrm{~mm}$ and painted with black opaque paint. In a darkened environment, the volunteer remained standing, shirtless and barefoot, with his back to the Moiré grid, while the light, obliquely, fell on it a photo was obtained in a perpendicular plane to the grid, thus, generating the Moire Topography (Figure 1).

The Moire Topography were analyzed through a script validated by Silva Filho et al. ${ }^{(18)}$, which proposes a qualitative evaluation of the back posture in the three orthogonal planes. This allowed to verify, in the frontal plane, asymmetry and alignment of the spine in the cervical, thoracic and lumbar regions, and the unevenness of the scapulae. In the sagittal plane, asymmetries of the spine were verified in the cervical, thoracic and lumbar regions; and, in the transverse plane, the asymmetry between the scapulae.

\section{Flexibility Measure}

The flexibility was measured using a fleximeter (Sanny ${ }^{\circledR}$, São Paulo, Brazil), in which the Range of Motion (ROM) of

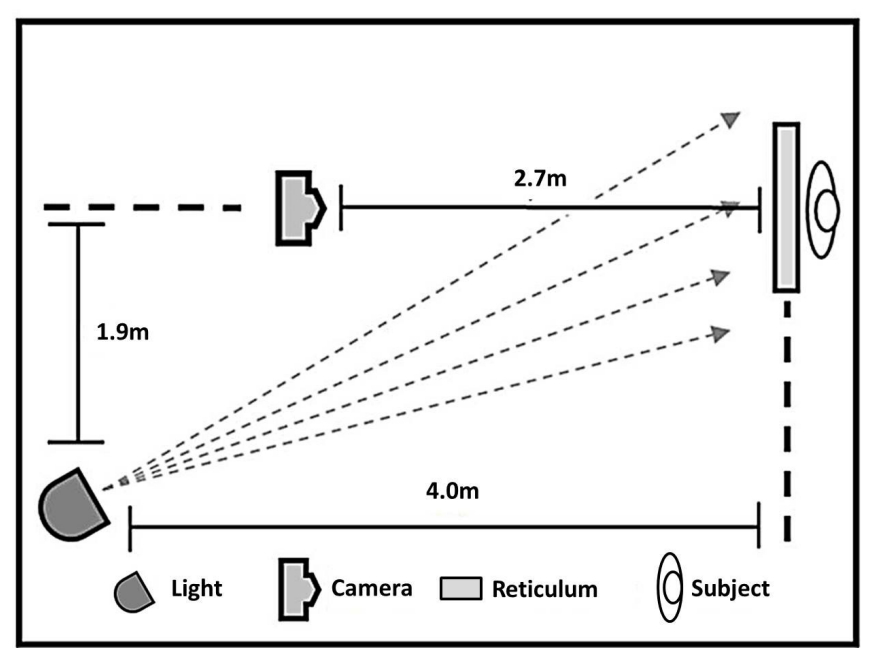

Figure 1. Scheme of postural evaluation with MST. Source: Silva Filho ${ }^{(18)}$. 
the ankle, knee, hip and spine trunk joints were measured. All movements were performed actively by the volunteer following the fleximeter user's manual.

\section{Muscle Stretching Exercises for Experimental Group}

The MSE program occurred during 8 weeks. Each session lasted 40 minutes with the guidance and supervision of a physical education teacher during the classes. The classes were offered in three days per week and each volunteer was to attend at least two days. The attendance frequency of the volunteers was recorded and monitored by the teacher. There was no sample death due to absence of the nurses during the classes.

The MSE program consisted of 8 static and active stretching exercises for upper limbs, trunk, hip and lower limbs, as following: 1) flexion of the cervical spine; 2 ) extension of the cervical spine; 3) stretching of the arms and forearms; 4) lateral trunk flexion to the right side; 5 ) lateral flexion of the trunk to the left side; 6) flexion of the spine (trunk); 7) extension of the spine (trunk); 8) maximum anterior flexion of seated trunk. For each exercise, four sets of active static stretching during 30s each with 30s of interval between the series were performed. To control the intensity, the volunteers were instructed to move slowly the muscle group until reach a mild discomfort, in order to avoid possible stretching and then to remain in that position during the stipulated time ${ }^{(19)}$. During all sessions, relaxation songs were used.

\section{Statistical treatment}

Statistical calculations were performed in software (SPSS $^{\mathrm{TM}} 21$, Chicago, IL, USA), and adopted the significance level of $p \leq 0.05$. Initially, the Shapiro-Wilk test was used to evaluate the data normality. Descriptive statistics were performed, with mean and standard deviation. To compare the sample characteristics between the two groups the T-independent test was applied. For the results of flexibility, the two-way ANOVA was used for repeated measures with Tukey test post-hoc. For the results concerning the body posture, the chi-square $\left(\mathrm{X}^{2}\right)$ test was used and a strength of association analysis between the two variables disposed in contingency table $2 \times 2$, through the Phi coefficient.

\section{RESULTS}

The sample characteristics are described in Table 1, in which the groups showed a significant difference among the averages with t-independent test, only to age ( $p=0.03$ ). However, in the anthropometric variables, no significant differences were observed.

\section{Experimental group and control group flexibility after the muscle stretching exercises program}

Table 2 shows the flexibility results of the groups after the intervention. The post hoc Tukey HSD for unequal samples found that the groups were homogeneous in terms of their initial ROM and that, only in the flexibility of the ankle flexion, knee flexion, spine (trunk) flexion and cervical spine extension of the EG, there were acute and chronic increases in flexibility. On the other hand, the ROM of the cervical spine, there was a significant difference in the acute effect for the EG. In the remaining ROM, no significant changes were observed.

\section{Acute and chronic effects of stretching in the body posture}

Table 3 shows the results regarding body posture before and after the MSE intervention. The individuals who did not present postural deviations before the beginning of the program ("pre" condition) were not considered in the analysis because the objective was precisely to verify the acute and chronic effects of MSE on the trunk body posture of the volunteers. For this reason, the indicated $\mathrm{n}$ in each evaluated postural deviation is different depending on the pre-condition of each individual.

The cervical deformities in the sagittal plane could not be visualized through the instrument, therefore, no statistical treatment was performed.

\section{DISCUSSION}

The present study aimed to verify the effects of MSE on body posture and on flexibility and in nurses. As acute effect, i.e., after a training session, it was speculated that the muscle stretching exercises could reduce the level of muscle activation and fatigue ${ }^{(20)}$, which could cause attenuation of functional

Table 1. Sample characteristics and comparing among the averages with t-independent test:

\begin{tabular}{|c|c|c|c|c|c|c|}
\hline \multirow{2}{*}{ Variables } & \multicolumn{2}{|c|}{$E G(n=15)$} & \multicolumn{2}{|c|}{ CG (n=13) } & \multirow{2}{*}{$p$} & \multirow{2}{*}{ ES } \\
\hline & $\mu-S D$ & IC $95 \%$ & $\mu-S D$ & $\mathrm{Cl} 95 \%$ & & \\
\hline Age (years) & $47.4 \pm 9.5$ & $42.1-52.6$ & $39.15 \pm 9.6$ & $33.3-44.9$ & $0.03 *$ & 0.860 \\
\hline $\mathrm{BM}(\mathrm{kg})$ & $68.6 \pm 14.4$ & $60.6-76.6$ & $72.5 \pm 10.5$ & $66-78.8$ & 0.43 & 0.301 \\
\hline Height (m) & $1.60 \pm 0.07$ & $1.56-1.64$ & $1.64 \pm 0.07$ & $1.60-1.69$ & 0.14 & 0.570 \\
\hline$\%$ CG & $26.1 \pm 7.8$ & $24.7-30.5$ & $24.9 \pm 7.4$ & $20.4-29.4$ & 0.68 & 0.158 \\
\hline BMI & $26.5 \pm 5$ & $23.7-29.3$ & $26.6 \pm 2.9$ & $24.8-28.3$ & 0.97 & 0.013 \\
\hline WHR & $0.83 \pm 0.08$ & $0.78-0.87$ & $0.80 \pm 0.07$ & $0.76-0.85$ & 0.42 & 0.308 \\
\hline
\end{tabular}

Legend: $\mathrm{CG}=$ Control Group; $\mathrm{EG}=$ Experimental Group; $\mathrm{BM}=$ Body mass; $\mathrm{BMI}=$ Body mass index; $\mathrm{Cl}=$ Confidence Interval; WHR = Waist-hip ratio; $\mathrm{n}=\mathrm{number}$ of volunteers; $\mu=\mathrm{Mean}$; $\mathrm{SD}=$ Standard Deviation; $\mathrm{p}=$ statistical value; $\left({ }^{*}\right)=\mathrm{p}<0.05 ; \mathrm{ES}=$ Effect size. 
Table 2. MSE Program effect on the flexibility of the EG and CG.

\begin{tabular}{|c|c|c|c|c|}
\hline JA (degrees) & Pre & (Post) Acute & (Post) Chronic & $F \& p$ \\
\hline$A F-E G$ & $26.4 \pm 4$ & $28.7 \pm 4.3^{*}$ & $29.3 \pm 4.5^{*}$ & $F=7.4 \& p=0.001$ \\
\hline$A F-C G$ & $28.5 \pm 9.3$ & $28.9 \pm 8.9$ & $28.3 \pm 8.7$ & \\
\hline$A E-E G$ & $29.7 \pm 9.7$ & $31.2 \pm 9.2$ & $29.2 \pm 9.2$ & $F=1.6 \& p=0.19$ \\
\hline$A E-C G$ & $30.9 \pm 11.7$ & $31 \pm 12.2$ & $31 \pm 12$ & \\
\hline $\mathrm{KF}-\mathrm{EG}$ & $119.8 \pm 11.8$ & $123.7 \pm 11.5^{*}$ & $122.3 \pm 11.8^{*}$ & $F=22.2 \& p=0.001$ \\
\hline $\mathrm{KF}-\mathrm{CG}$ & $116.1 \pm 11.3$ & $115.4 \pm 11.2$ & $114.5 \pm 10.6$ & \\
\hline$H F-E G$ & $96.1 \pm 11.5$ & $100.8 \pm 9.1$ & $100.2 \pm 9.8$ & $F=1.08 \& p=0.34$ \\
\hline $\mathrm{HF}-\mathrm{CG}$ & $93.4 \pm 20.3$ & $92 \pm 29.8$ & $95.4 \pm 23.2$ & \\
\hline$F S-E G$ & $14.4 \pm 6.6$ & $16.4 \pm 5.6^{*}$ & $15.9 \pm 5.9 *$ & $F=4.4 \& p=0.01$ \\
\hline $\mathrm{FS}-\mathrm{CG}$ & $14.9 \pm 6$ & $15 \pm 6.1$ & $14.9 \pm 6.1$ & \\
\hline$S F-E G$ & $13.9 \pm 5.8$ & $15.2 \pm 5.8$ & $14.8 \pm 6.1$ & $F=0.68 \& p=0.51$ \\
\hline $\mathrm{SF}-\mathrm{CG}$ & $12.6 \pm 3.8$ & $13.3 \pm 3.4$ & $14 \pm 4.8$ & \\
\hline$C S F-E G$ & $63.8 \pm 12.7$ & $67 \pm 12.4$ & $64.9 \pm 12.8$ & $F=2.4 \& p=0.09$ \\
\hline CSF - CG & $61.3 \pm 15.3$ & $61.3 \pm 15.3$ & $57.3 \pm 20.4$ & \\
\hline CSE - EG & $55.8 \pm 12.8$ & $58.2 \pm 13^{*}$ & $57 \pm 13.6$ & $\mathrm{~F}=3.8 \& \mathrm{p}=0.02$ \\
\hline CSE - CG & $52.6 \pm 12.3$ & $52.6 \pm 13$ & $50.9 \pm 16$ & \\
\hline
\end{tabular}

Legend: $\mathrm{JA}=$ Joint angle; $\mathrm{EG}$ : Experimental Group; $\mathrm{CG}=$ Control Group; $\mathrm{P}=$ probability of chance; $\mathrm{AF}=$ Ankle flexion; $\mathrm{AE}=\mathrm{Ankle}$ extension; $\mathrm{KF}=\mathrm{knee}$ flexion; $\mathrm{SF}=\mathrm{Spine}$ (trunk) Flexion; $\mathrm{EC}=$ Extension of the vertebral column (trunk); HF = Hip flexion; $\mathrm{CSF}=$ Cervical spine flexion; $\mathrm{CSE}=$ Cervical spine extension; $(*)=\mathrm{Significant}$ difference $(p<0.05)$.

Table 3. Effect of the MSE program on the body posture between the EG and CG.

\begin{tabular}{|c|c|c|c|c|c|c|c|c|c|c|c|c|c|}
\hline \multirow{2}{*}{\multicolumn{2}{|c|}{$\begin{array}{l}\text { Postural deviation by planes and } \\
\text { regions of the spine }\end{array}$}} & \multicolumn{4}{|c|}{ Acute effect } & \multicolumn{4}{|c|}{ Chronic effect } & \multirow{2}{*}{\multicolumn{2}{|c|}{ Acute effect }} & \multirow{2}{*}{\multicolumn{2}{|c|}{ Chronic effect }} \\
\hline & & \multicolumn{2}{|c|}{ It had effect } & \multicolumn{2}{|c|}{$\begin{array}{l}\text { It did not } \\
\text { have effect }\end{array}$} & \multicolumn{2}{|c|}{ It had effect } & \multicolumn{2}{|c|}{$\begin{array}{l}\text { It did not } \\
\text { have effect }\end{array}$} & & & & \\
\hline \multirow{10}{*}{ 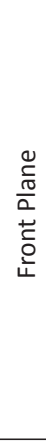 } & SC Asymmetries & EG & CG & EG & CG & EG & CG & EG & CG & $\mathrm{X}^{2}$ & Phi & $\mathrm{X}^{2}$ & Phi \\
\hline & Cervical Region & 4 & 0 & 4 & 7 & 4 & 0 & 4 & 7 & $0.02 *$ & $0.56^{c}$ & $0.02 *$ & $0.56^{c}$ \\
\hline & Thoracic Region & 4 & 0 & 10 & 11 & 4 & 0 & 10 & 11 & $0.05^{*}$ & $0.38^{b}$ & $0.05^{*}$ & $0.38^{b}$ \\
\hline & Lumbar Region & 2 & 0 & 13 & 13 & - & - & - & - & 0.17 & $0.25^{a}$ & - & - \\
\hline & SC Alignment & & & & & & & & & & & & \\
\hline & Cervical Region & 7 & 0 & 8 & 10 & 5 & 0 & 10 & 10 & $0.01^{*}$ & $0.51^{c}$ & $0.04^{*}$ & $0.41^{c}$ \\
\hline & Thoracic Region & 3 & 1 & 11 & 9 & 3 & 3 & 11 & 7 & 0.45 & $0.15^{\mathrm{a}}$ & 0.63 & $0.09^{a}$ \\
\hline & Lumbar Region & 2 & 0 & 12 & 13 & 2 & 0 & 12 & 13 & 0.15 & $0.27^{a}$ & 0.15 & $0.27^{a}$ \\
\hline & Scapula Unevenness & & & & & & & & & & & & \\
\hline & Leveled or uneven & 3 & 0 & 11 & 7 & 7 & 2 & 7 & 5 & 0.18 & $0.29^{a}$ & 0.35 & 0.20 \\
\hline \multirow{6}{*}{ 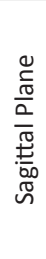 } & SC Asymmetries & & & & & & & & & & & & \\
\hline & Cervical Region & & & & & & & & & & & & \\
\hline & Thoracic Region & - & - & - & - & 2 & 0 & 11 & 6 & - & - & 0.31 & $0.23^{\mathrm{a}}$ \\
\hline & Lumbar Region & 3 & 0 & 4 & 5 & 4 & 0 & 3 & 5 & 0.09 & $0.49^{c}$ & $0.03^{*}$ & $0.60^{c}$ \\
\hline & Transverse Plane & & & & & & & & & & & & \\
\hline & Scapula Unevenness & 5 & 0 & 3 & 6 & 5 & 2 & 3 & 4 & $0.01^{*}$ & $0.64^{c}$ & 0.28 & $0.29^{a}$ \\
\hline
\end{tabular}

Legend: SC=Spinal column; EG=Experimental group; $C G=$ Control group; $X^{2}=$ Chi-square test; $\left({ }^{*}\right)=$ Significant difference $(p<0.05) ;$ Phi= $(a)$ small effect $(0.10)$, (b) medium effect $(0.30)$ and (c) large effect. (0.50).

postural deviations. As a chronic effect, i.e. after eight weeks of MSE classes, could occur reduction of muscle imbalance ${ }^{(21)}$, increasing the muscle flexibility, influencing ROM and postural deviations and increasing flexibility.

In this study, MSE promoted significant alterations of acute and chronic forms in the concavities of the spine in the cervical and thoracic regions, and in the frontal alignment of the cervical region. Also, a significant reduction in lumbar curvature could be noted after the 8 weeks of training. Finally, a significant acute reduction was detected in deformity of the scapulae. The other observed postural deviations did not change significantly.

Although, in the literature, there is still controversy about the real effects of MSE for correcting postural deviations, in 
the systematic review by Silva Filho, Gurgel and Porto ${ }^{(12)}$, the authors suppose that the lack of consensus may be occurring by handling inadequate physical training variables, the subjectivity of the employed postural evaluation method and/or the inadequate methodological description found in the studies which were willing to deal with the subject. Thus, the present study proposed to fill these scientific gaps.

Regarding the acute effect of MSE on body posture, the results are in agreement with López-Minarro et al. (22) study, which evaluated the acute effect of MSE on 55 individuals after a stretching session of 4 exercises of hip flexion, 3 sets of 20s of voltage for 30 s intervals, showed significant changes in curvature of the spine and position of the pelvis. However, in the study by Campbell ${ }^{(23)}$, which verified the acute effect of MSE on 16 men and women with a mean age of 23 years, there were no significant changes in curvature of the spine, the lateral inclination of the trunk and sacral slope, after exposure of volunteers to a 12-min hip flexion at $90^{\circ}$. It is believed that the results of Camargo ${ }^{(23)}$ are explained because the author used a different protocol than is recommended by the American College of Sports Medicine (24); That fact did not occur in this research and in the study of López-Miñarro et al. ${ }^{(22)}$. Instead, in both studies ${ }^{(22,23)}$, there was not CG, which becomes crucial for providing secure evidence when working with proposed interventions.

Regarding chronic effect of MSE in body posture, significant changes were observed in the spine in the concavities of the cervical and thoracic regions, asymmetries in the cervical region and on lumbar region curvature, as in accordance with outcomes in other studies ${ }^{(25,26)}$, but not in accordance with the study by Li et al. (27).

Hashimoto et al. ${ }^{(25)}$ studied 11 individuals in average age of 37.1 years, during 3 to 4 months, and 20 sessions applied of one hour each, active stretching, 2 times per week; at the end of the study, the volunteers presented significant improvements in the leveling of the shoulders, hip, trunk and head. Finally, Muyor et al. ${ }^{(26)}$ evaluated 58 women, mean age 44.2 years, in which were subjected to 12 weeks of stretching of posterior thigh muscles, 3 times a week and, at the end of the study, they showed a more aligned thoracic curve.

In contrast to the abovementioned studies, the study of Li et al. ${ }^{(27)}$, conducted with 58 men and adult women for 3 weeks, with the intervention a series of 15 s voltage by $15 \mathrm{~s}$ of static stretching rest of the posterior chain, at a frequency of 10 times per day, did not notice, at the end of the study, significant alterations in the pelvic-lumbar posture of the volunteers. It is assumed that the effects of MSE were not observed due to the exercise program model, because, for such exercises cause physiological changes over time, the elongation should be at least 20 to 30 s voltage ${ }^{(24)}$.

The present study when compared to studies which also observed positive effects of MSE on body posture ${ }^{(25,26)}$, presented a more detailed description of the methodological aspects to conduct the study, since the variables were presented as training volume, intensity, periodization, recovery, and information about the method of postural evaluation. The lack of information on the methods may be a limiting factor to obtain reliable evidence about the proposed intervention.

The flexibility data showed that the EG presented acute and chronic differences in some joints. Considering that the MSE are the means to work flexibility as a physical valence, there is evidence that a less rectified posture is related to poor flexibility and muscle weakness or imbalance ${ }^{(21)}$. It is believed that the findings of the present study only strengthen the evidence already presented by other studies, however further studies on the subject are suggested, as it was not possible to find alterations in all investigated joints.

Regarding the nurses, the findings of this research are very importance, since it is known that these professionals are usually subjected to a work which expose them to harmful postures ${ }^{(28)}$. In 2012, the Nursing Assistants and Nurses occupied the second and fifth places in the number of non-fatal occupational accidents, respectively, among all occupations in the United States ${ }^{(29)}$. According to Jerome and $\mathrm{Cruz}^{(30)}$, these musculoskeletal injuries related to nurses generate high costs on productivity, absenteeism and quality of life, requiring, therefore, occupational disease prevention strategies.

\section{CONCLUSION}

It is concluded that, for the sample of nurses in the present study, the MSE promoted positive and chronic positive changes in the concavities of the vertebral column in the cervical and thoracic regions and in the alignment of the cervical region. Also, there was a reduction in scapulae deformity just after the MSE session and reduced curvature of the lumbar spine after 8 weeks of training. The MSE increased the flexibility of these professionals soon after one session and after 8 weeks of training.

\section{ACKNOWLEDGEMENTS}

The National Scientific and Technological Development Council (CNPq) and the Foundation Carlos Chagas Filho Research of the State of Rio de Janeiro - (FAPERJ) for granted scholarship.

\section{AUTHORS' CONTRIBUTIONS}

JNSF: data collection; Analysis and interpretation of data; Writing of the manuscript; JLG: data analysis and interpretation; Critical revision of the manuscript regarding important intellectual content; EBS: writing of the manuscript; FP: research design and design; Analysis and interpretation of data; Obtaining funding; Writing of the manuscript; Critical revision of the manuscript regarding important intellectual content.

\section{CONFLICTS OF INTEREST}

The author(s) declare that they have no competing interests. 


\section{AUTHOR DETAILS}

${ }^{1} \mathrm{MSc}$, Research Group Occupational in Health and Exercise (GPSOEF), State University of Rio de Janeiro (UERJ), Rio de Janeiro (RJ), Brazil.

${ }^{2} \mathrm{PhD}$, Institute of Physical Education (IEF), Fluminense Federal University (UFF), Niterói (RJ), Brazil.

${ }^{3} \mathrm{PhD}$, Institute of Physical Education and Sports (IEFD), State University of Rio de Janeiro (UERJ), Rio de Janeiro (RJ), Brazil.

\section{REFERENCES}

1. Dolphens M, Cagnie B, Coorevits P, Vanderstraeten G, Cardon G, D'hooge $R$, et al. Sagittal standing posture and its association with spinal pain [Internet]. Spine; 2012 [cited 2017 Jan 27];37(19):1657-66.

2. Moura Neto $A B$ de, Silva $M C$ da. Diagnóstico das condições de trabalho, saúde e indicadores do estilo de vida de trabalhadores do transporte coletivo da cidade de Pelotas - RS. Revista Brasileira de Atividade Física \& Saúde. 2013;17(5):347-58.

3. Polga DJ, Beaubien BP, Kallemeier PM, Schellhas KP, Lew WD, Buttermann $\mathrm{GR}$, et al. Measurement of in vivo intradiscal pressure in healthy thoracic intervertebral discs [Internet]. Spine; 2004;29(12):1320-4.

4. Kanthack Paccini M, Serpeloni Cyrino E, Fátima Glaner M. Efeito de exercícios contra-resistência na postura de mulheres. J. Phys. Educ. 2007;18(2):169-75.

5. World Health Organization. Identification and control of work-related diseases [Internet]. Geneva: 1985 [cited 2017 Jan 27]. Available from: http://apps.who.int/iris/bitstream/10665/40176/1/WHO_TRS_714.pdf.

6. Marziale MHP, Melo MRA, Silva EM. A postura corporal adotada pela enfermeira durante a execuçäo de seu trabalho. Rev. bras. saúde ocup. 1991;19(73):19-24.

7. Engels JA, Van Der Gulden JWJ, Senden TF, Hertog C, Kolk JJ, Binkhorst RA. Physical work load and its assessment among the nursing staff in nursing homes. J Occup Environ Med. 1994;36(3):338-45.

8. Batiz EC, Vergara LGL, Licea OEA. Análise comparativa entre métodos de carregamento de cargas e análise postural de auxiliares de enfermagem. Produção. 2012;22(2):270-83.

9. Zanon E, Marziale MHP. Avaliação da postura corporal dos trabalhadores de enfermagem na movimentação de pacientes acamados. Rev Esc Enferm USP. 2000;34(1):26-36.

10. Garber CE, Blissmer B, Deschenes MR, Franklin BA, Lamonte MJ, Lee $\mathrm{I}-\mathrm{M}$, et al. American College of Sports Medicine position stand. Quantity and quality of exercise for developing and maintaining cardiorespiratory, musculoskeletal, and neuromotor fitness in apparently healthy adults: guidance for prescribing exercise. Medicine and science in sports and exercise. 2011;43(7):1334-59.

11. Burke TN, França FJR, de Meneses SRF, Cardoso VI, Marques AP. Postural control in elderly persons with osteoporosis: efficacy of an intervention program to improve balance and muscle strength: a randomized controlled trial. American journal of physical medicine \& rehabilitation. 2010;89(7):549-56.

12. Da Silva Filho JN, Gurgel JL, Porto F. Efeitos de exercícios de alongamento para correção postural: revisão sistemática [Internet]. MTP\&RehabJournal; 2014;12(12):544-66.
13. Porto F, Espinosa G, Vivian RC, Itaborahy A da S, Montenegro RA, Farinatti $P$ de TV, et al. O exercício físico influencia a postura corporal de idosas? [Internet]. Motriz: Revista de Educação Física; 2012;18(3):487-94.

14. Cunha ACV, Burke TN, França FJR, Marques AP. Effect of global posture reeducation and of static stretching on pain, range of motion, and quality of life in women with chronic neck pain: a randomized clinical trial. Clinics. 2008;63(6):763-70.

15. De Castro AB. Handle with care: The American Nurses Association's Campaign to address work-related musculoskeletal disorders. Online Journal of Issues in Nursing. 2004;9(3).

16. Falqueto FA, Helrigle $C$, Malysz T. Prevalência de alterações posturais em praticantes regulares de musculação. Ter Man. 2011;41(9):51-6.

17. Porto F, Gurgel JL, Russomano T, Farinatti PTV. Shadow Moire Technique to measure deformity of the trunk surface in the elderly: a populationbased study [Internet]. In: Bessette A, Rousseau CM, editors. Scoliosis: causes, symptoms and treatment. New York: Nova Science Publishers, Inc.(Nova Biomedical); 2012. p. 73-90.

18. Da Silva Filho JN, Batista LA, Gurgel JL, Porto F. Shadow moiré technique for postural assessment: qualitative assessment protocol by intra- and inter-rater evaluation. J. Phys. Ther. Sci. 2017;29(2).

19. De Weijer VC, Gorniak GC, Shamus E. The effect of static stretch and warmup exercise on hamstring length over the course of 24 hours. Journal of Orthopaedic \& Sports Physical Therapy. 2003;33(12):727-33.

20. Yahia A, Jribi S, Ghroubi S, Elleuch M, Baklouti S, Elleuch MH. Evaluation of the posture and muscular strength of the trunk and inferior members of patients with chronic lumbar pain. Joint Bone Spine. 2011;78(3):291-7.

21. Granito RN. Efeitos do envelhecimento e da osteoporose na cifose torácica, na propriocepção e no torque dos músculos do tronco [master's thesis]. São Paulo: Universidade Federal de São Carlos; 2005.

22. López-Miñarro P, Muyor J, Belmonte F, Alacid F. Acute effects of hamstring stretching on sagittal spinal curvatures and pelvic tilt. Journal of human kinetics. 2012;31:69-78.

23. Camargo LC. Efeitos imediatos do alongamento global na retração da cadeia muscular porterior-resposta eletromiografica, dinamometria e avaliação postural. 2007;

24. American College of Sports Medicine. ACSM's guidelines for exercise testing and prescription. Lippincott Williams \& Wilkins; 2006.

25. Hashimoto B, Takahagi LS, Pachioni CAS. Análise da postura de participantes de um programa postural em grupo. Revista Eletrônica de Fisioterapia da FCT-UNESP. 2009;1(1):46-62.

26. Muyor JM, López-Miñarro PA, Casimiro AJ. Effect of stretching program in an industrial workplace on hamstring flexibility and sagittal spinal posture of adult women workers: a randomized controlled trial. Journal of back and musculoskeletal rehabilitation. 2012;25(3):161-9.

27. Li Y, McClure PW, Pratt $N$. The effect of hamstring muscle stretching on standing posture and on lumbar and hip motions during forward bending. Physical therapy. 1996;76(8):836-45.

28. Schall MC, Fethke NB, Chen H. Working postures and physical activity among registered nurses. Applied ergonomics. 2016;54:243-50.

29. US Department of Labor. Nonfatal occupational injuries and illnesses requiring days away from work, 2012. 2012 [cited 2017 Jan 27];1-33.

30. Jerónimo J, Cruz A. Estudo da prevalência e fatores de risco de lesões musculoesqueléticas ligadas ao trabalho em enfermeiros. Revista Investigação em Enfermagem. 2014;9(2):35-46. 